\title{
Comparative study of Adenoidectomy by Endoscopic Transoral Suction Coagulation Versus the Traditional Method
}

Abdelaziz Elsherif, Ahmed Mohamed Nagy Abdul Raaof*, Sabry Habashy Issa

Department of Otorhinolaryngology, Faculty of Medicine - Al Azhar University-Asyut

*Corresponding author: Ahmed Mohamed Nagy Abdul Raaof, Mobile: (+20) 01020726697,

E-Mail: dr_ahmednagy95@yahoo.com

\section{ABSTRACT}

Background: Adenoidectomy is one of the most common procedures performed by otorhinolaryngologists. Previously, suction cautery was used for haemostasis following curettage adenoidectomy. Whereas more recently, the entire procedure has been performed using this technique, and it has now been accepted as a suitable technique, especially in the pediatric population.

Objective: To compare two different techniques for adenoidectomy, one is traditional adenoidectomy and the other is the endoscopic transoral adenoidectomy by suction diathermy.

Patients and methods: This study included 100 patients (62 males and 38 females) attended to the Otorhinolaryngology Outpatient Clinic of Al-Azhar University Hospital in Assiut and diagnosed as adenoid hypertrophy through the period from November 2019 to March 2020.

Results: The average operative time of traditional method was 9.9 minutes (range: 7 to 12 minutes), which is longer than that of adenoidectomy by suction diathermy where it was7.2 minutes (range: 4 to 10 minutes) also the intra operative blood loss was markedly lower in adenoidectomy by suction diathermy. It was $5.7 \mathrm{ml}$ (range: 3 to $7 \mathrm{ml}$ ) while it was $27.3 \mathrm{ml}$ (range: 21 to $32 \mathrm{ml}$ ) in the traditional method. Post-operative complications in our study include post-operative hemorrhage, velopharyngeal insufficiency and recurrence, which was higher in the traditional method. Post adenoidectomy healing time was 14 days for the traditional method (range: 13 to15 days), which is shorter than that of suction diathermy where it was 18 days (range: 17 to 20 days).

Conclusion: Adenoidectomy by endoscopic transoral suction diathermy is more safe and effective than adenoidectomy by traditional curatte in treatment of patients with hypertrophied adenoid with less complication.

Keywords: Adenoidectomy, Endoscopic Transoral Suction Coagulation, Versus the Traditional Method.

\section{INTRODUCTION}

Adenoidectomy alone or in association with tonsillectomy is one of the oldest and most commonly performed ENT surgical procedures. It is typically carried out in children for conditions such as adentonsillar hypertrophy, obstructive sleep apnea, otitis media with effusion, recurrent otitis media and nasal obstruction. Historically recommended instrumentation for performing adenoidectomy has varied from the surgeon's fingernail, a steel nail, cutting or biting forceps, adenotomes and adenoid curettes ${ }^{(\mathbf{1})}$.

Complete removal of the adenoids is difficult to determine when performing curette adenoidectomy. The importance of removing laterally based adenoidal tissue when performing adenoidectomy for otitis media with effusion has been well described in earlier reports (2). The search for an instrument to perform bloodless adenoidectomy successfully under direct vision has been the topic of numerous clinical trials. A number of instruments have been implemented to perform adenoidectomies, including radio frequency, suction diathermy, microdebrider and laser ${ }^{(3,41)}$.

One method that seems to be gaining popularity is transoral suction diathermy adenoidectomy while using 70-degree endoscope. The suction coagulator was developed in the 1970s. The first experimental use described in the literature was in control of upper gastrointestinal hemorrhage in dogs.
Subsequently, six patients with active bleeding gastric lesions underwent endoscopic mucosal coagulation $^{(5)}$.

It was not utilized in adenoid surgery for a further 10 years. Initially the instrument was used for hemostasis following curettage of the adenoids ${ }^{(\boldsymbol{})}$. More recently, the whole procedure has been performed using suction diathermy ${ }^{(7)}$. This approach provides a direct-targeted route to the nasopharynx, improved visualization, a bloodless surgical field and improved evaluation of the adenoids, the Eustachian tube and the posterior nasal choanae. The improved visualization enables the surgeon to remove choanal adenoids, which are present in $10 \%$ of patients ${ }^{(\mathbf{8})}$. It also allows the surgeon to avoid adjacent structures such as the Eustachian tube orifices. Adenoidal tissue encroaching on the Eustachian cushions can be suctioned medially and then ablated, thus avoiding trauma to the Eustachian tube openings. The benefit of suction diathermy in reducing intraoperative blood loss and post-operative bleeding has been well documented ${ }^{(9)}$. Therefore, it is essential to compare this relatively new method with the established conventional method. This work aimed to compare two different techniques for adenoidectomy, one is traditional adenoidectomy and the other is the endoscopic transoral adenoidectomy by suction diathermy. 


\section{PATIENTS AND METHODS}

This study included 100 patients diagnosed as adenoid hypertrophy (62 males and 38 females) attended to the Otorhinolaryngology Outpatient Clinic, Al-Azhar University Hospital, Assiut through the period from November 2019 to March 2020.

\section{Inclusion criteria:}

1. Age: children $2-12$ years old only.

2. Sex: both males and females.

3. Persons were selected from the Otorhinolaryngology Outpatient Clinic of AlAzhar University Hospital, Assiut.

4. All patients were generally well and fit for surgery.

5. Level of hemoglobin of patients ranged from 10 $13 \mathrm{gm} / \mathrm{dl}$.

\section{Exclusion criteria:}

1. Patients with recent upper respiratory tract infection.

2. Evidence of any bleeding disorders.

3. Patients with Cleft palate.

4. Patients with atrophic rhinitis

5. Patients with nasal obstruction due to other causes such as inferior turbinate hypertrophy, deviated nasal septum and antrochoanal polyp.

6. Patient with recurrent adenoid.

\section{Patients were divided into two groups and each group consisted of 50 patients:}

Group I [50 patients]: adenoidectomy was done by traditional method.

Group II [50 patients]: adenoidectomy was done by endoscopic suction diathermy.

\section{All patients were submitted to the following:}

\section{1-History:}

- Personal History.

- Complaint and its duration.

- History of present illness: Nasal obstruction, nasal discharge, sore throat, hearing loss and nocturnal enuresis.

- Past history.

- Family history.

\section{2-Examination:}

\section{A-General examination:}

- General Appearance of the patient (adenoid facies).

- Conscious level, alertness and cooperative patient or not.

- Colour: Pallor, Jaundice or cyanosis.

- Body built and nourishment.

- Vital signs: pulse, temperature, blood pressure and respiratory rate.

\section{B-Otorhinolaryngology examination:}

- Nasal examination.

- Oropharyngeal examination.

- Ear examination.
3-Investigations:

A-Radiological:

- Plain X-ray soft tissue lateral view nasopharynx.

- Pure tone audiometry: CHL.

- Tympanometry: Type B tympanogram.

B- Laboratory: Routine Lab. investigations for anaethesia fitness e.g. CBC, Coagulation profile ...etc.

Pre-operative phoniatric consultation has been done for suspected patients with hypernasality.

\section{Surgery \& Treatment:}

- Pre-operative medical treatment of acute infections.

- The patients were operated by traditional or endoscopic adenoidectomy.

- Post-operative course of antibiotics for a week for all patients.

- The patients were discharged when fit and called for follow-up on $1^{\text {st }}$ week and during the following two weeks according to the healing process and $6^{\text {th }}$ months from the date of surgery.

- During these visits, the patients were asked for relief of symptoms and were examined clinically.

- Post-operative nasal endoscopy was done after 6 months for all patients to detect recurrence.

- X-ray lateral view nasopharynx with open mouth is done 6 months post-operative to detect the degree of improvement and recurrence if present.

Ethical approval and written informed consent: An approval of the study was obtained from AlAzhar University Academic and Ethical Committee. Every patient signed an informed written consent for acceptance of the operation.

\section{Statistical analysis}

The collected data were revised, organized, tabulated and statistically analyzed using statistical package for social sciences (SPSS) version 23.0 for windows. Data were presented as the Mean \pm standard deviation (SD), frequency, and percentage. Continuous variables were compared by the Students't test (twotailed). Categorical variables were compared using the chi-square $\left(\chi^{2}\right)$ and Fisher's exact tests (if required). The level of significance was accepted if the $\mathrm{P}$ value $\leq$ 0.05 .

\section{RESULTS}

The patients' age ranged from 2 to 12 years. The mean age of group I was 6.8 years and that of group II was 7.2 years. In the present study, the youngest patient was 2 years old while the oldest was 12 years old. No statistical significant difference $(\mathbf{p}>\mathbf{0 . 0 5})$ between studied groups as regard age. There were 62 males accounting for $62 \%$ totally and 38 females accounting for $38 \%$ totally. In group I, 30 males and 20 females while in group II, 32 males and 18 females. No statistical significant difference $(\mathbf{p}>\mathbf{0 . 0 5})$ between studied groups as regards sex (Table 1). 
Table (1): Comparison between studied groups as regards age and sex

\begin{tabular}{|c|c|c|c|c|}
\hline & & Group I $(\mathbf{N}=\mathbf{5 0})$ & Group II $(N=50)$ & P-value \\
\hline \multirow{2}{*}{$\begin{array}{c}\text { Age } \\
\text { (years) }\end{array}$} & Mean \pm SD & $6.8 \pm 1.2$ & $7.2 \pm 1.2$ & \multirow{2}{*}{$0.085 \mathrm{NS}$} \\
\hline & Range & $2-10$ & $4-12$ & \\
\hline \multirow{2}{*}{ Sex } & Male (N/\%) & $30(60 \%)$ & $32(64 \%)$ & \multirow{2}{*}{$0.680 \mathrm{NS}$} \\
\hline & Female (N/\%) & $20(40 \%)$ & $18(36 \%)$ & \\
\hline
\end{tabular}

NS: p-value $>0.05$ is considered non-significant

The most common presentation of both groups was snoring affecting 47 patients (94\%) of group I and 45 patients (90\%) of group II. It was followed by mouth breathing 35 patients (70\%) in group I and 30 patients $(60 \%)$ in group II then OSA, nasal discharge and hearing loss respectively. No statistical significant difference (p > 0.05) between studied groups regarding symptoms and signs (Table 2).

Table (2): Comparison between studied groups as regards symptoms \& signs

\begin{tabular}{|c|l|r|r|r|r|c|c|}
\hline \multicolumn{2}{|c|}{} & \multicolumn{2}{c|}{ Group I (N = 50) } & \multicolumn{2}{c|}{ Group II (N = 50) } & $\mathbf{X}^{\mathbf{2}}$ & P-value \\
\hline \multirow{3}{*}{$\begin{array}{c}\text { Sympt } \\
\text { oms \& }\end{array}$} & Snoring & 47 & $94 \%$ & 45 & $90 \%$ & 0.54 & $0.461 \mathrm{NS}$ \\
\cline { 2 - 8 } signs & OSA & 15 & $30 \%$ & 16 & $32 \%$ & 0.04 & $0.828 \mathrm{NS}$ \\
\cline { 2 - 8 } & Nasal discharge & 6 & $12 \%$ & 5 & $10 \% \%$ & 0.102 & $0.749 \mathrm{NS}$ \\
\cline { 2 - 8 } & Mouth breathing & 35 & $70 \%$ & 30 & $60 \%$ & 1.09 & $0.294 \mathrm{NS}$ \\
\cline { 2 - 8 } & Hearing loss & 12 & $24 \%$ & 11 & $22 \%$ & 0.05 & $0.812 \mathrm{NS}$ \\
\hline
\end{tabular}

$\mathrm{X}^{2}$ : Chi-square test. $\quad$ NS: $\mathrm{p}$-value $>0.05$ is considered non-significant.

An adenoidectomy alone was done in 16 patients (32\%) of group I and in 15 patients $(30 \%)$ of group II. Adenoidectomy and bil G tube insertion was done in 10 patients (20\%) of group I and in 9 patients (18\%) of group II. An adenotonsillectomy was done in 16 patients (32\%) of group I and in 16 patients $(32 \%)$ of group II. adenotonsillectomy with bil G tube insertion was done in 8 patients $(16 \%)$ of group I and in $10(20 \%)$ patients of group II. No statistical significant difference $(\mathbf{p}>\mathbf{0 . 0 5})$ between studied groups as regards operation type (Table 3$)$.

Table (3): Comparison between studied groups as regards type of operation

\begin{tabular}{|c|c|c|c|c|c|c|c|}
\hline & & \multicolumn{2}{|c|}{ Group I $(\mathbf{N}=\mathbf{5 0})$} & \multicolumn{2}{|c|}{ Group II $(\mathbf{N}=\mathbf{5 0})$} & $\mathbf{X}^{2}$ & P-value \\
\hline \multirow{4}{*}{ } & Adenoidectomy & 16 & $32 \%$ & 15 & $30 \%$ & \multirow{4}{*}{$\begin{array}{l}0.3 \\
07\end{array}$} & \multirow{4}{*}{$0.958 \mathrm{NS}$} \\
\hline & $\begin{array}{c}\text { Adenoidectomy + bil. G } \\
\text { tube insertion }\end{array}$ & 10 & $20 \%$ & 9 & $18 \%$ & & \\
\hline & Adenotonsillectomy & 16 & $32 \%$ & 16 & $32 \%$ & & \\
\hline & $\begin{array}{c}\text { Adenotonsillectomy + } \\
\text { bil. G tube insertion }\end{array}$ & 8 & $16 \%$ & 10 & $20 \%$ & & \\
\hline
\end{tabular}

$\mathrm{X}^{2}$ : Chi-square test. $\quad$ NS: $\mathrm{p}$-value $>0.05$ is considered non-significant.

The average operative time was 9.9 minutes for group I (range: 7 to 12 minutes) and 7.2 minutes for group II (range: 4 to 10 minutes), which was statistically significant $(\mathbf{p}<\mathbf{0 . 0 0 1})$. High statistical significant difference $(\mathbf{p}<$ 0.001) between studied groups regarding operative time. The average blood loss was $27.3 \mathrm{ml}$ for group I (range: 21 to $32 \mathrm{ml}$ ) and $5.7 \mathrm{ml}$ for group II (range: 3 to $7 \mathrm{ml}$ ), which is highly statistically significant $(\mathbf{p}<\mathbf{0 . 0 0 1})$. High statistical significant difference $(\mathbf{p}<\mathbf{0 . 0 0 1})$ between studied groups regarding blood loss (Table 4$)$.

Table (4): Comparison between studied groups as regards operative time and blood loss

\begin{tabular}{|c|c|c|c|c|c|}
\hline \multicolumn{2}{|c}{} & Group I (N = 50) & Group II (N = 50) & T & P-value \\
\hline \multirow{2}{*}{$\begin{array}{c}\text { Operative time } \\
(\mathbf{m i n})\end{array}$} & Mean \pm SD & $9.9 \pm 1.3$ & $7.2 \pm 0.9$ & \multirow{1}{12.0}{} & \multirow{2}{*}{$\mathbf{0 . 0 0 1}$ HS } \\
\cline { 2 - 4 } & Range & $7-12$ & $4-10$ & $\mathbf{7}$ & \\
\hline \multirow{2}{*}{$\begin{array}{c}\text { Blood loss } \\
(\mathbf{m l})\end{array}$} & Mean \pm SD & $27.3 \pm 3.9$ & $5.7 \pm 1.8$ & \multirow{2}{*}{35.6} & $<\mathbf{0 . 0 0 1}$ HS \\
\cline { 2 - 4 } & Range & $21-32$ & $3-7$ & & \\
\hline
\end{tabular}

T: Independent sample T test. $\quad$ HS: p-value $<0.001$ is considered highly significant.

There was post-operative complications in the form of post-operative bleeding. There was no primary bleeding in both groups. There was reactionary adenoid bleeding in 1 case (2\%) of group I with no cases in group II. In addition, there was secondary adenoid bleeding in one case $(2 \%)$ of group I with no secondary bleeding in group I. Bleeding was controlled conservatively. There was velopharyngeal insufficiency in one case (2\%) of group I with no cases in group II. This patient was followed up for 3 months with spontaneous improvement. By nasal endoscopic examination with cooperative patients and nasopharyngeal $x$-ray lateral view at the end of 6 months follow-up, there were 4 patients (8\%) with recurrent adenoid hypertrophy in group I with one case $(2 \%)$ of recurrence of adenoid hypertrophy in group II, which was statistically significant $(\mathrm{p}<0.05)$. This table showed no statistical significant difference (p-value $>\mathbf{0 . 0 5}$ ) between studied groups as regards post-operative complications (Table 5). 
Table (5): Comparison between studied groups as regards post-operative complications

\begin{tabular}{|c|l|c|c|c|c|c|c|}
\hline \multicolumn{2}{|c|}{ Post-op. complications } & \multicolumn{2}{c|}{$\begin{array}{c}\text { Group I } \\
(\mathbf{N = 5 0}\end{array}$} & \multicolumn{2}{c|}{$\begin{array}{c}\text { Group II } \\
(\mathbf{N = 5 0}\end{array}$} & $\mathbf{X}^{\mathbf{2}}$ & P-value \\
\hline \multirow{3}{*}{ Post op. bleeding } & Primary & 0 & $0 \%$ & 0 & $0 \%$ & ---- & --- \\
\cline { 2 - 8 } & Reactionary & 1 & $2 \%$ & 0 & $0 \%$ & 1.01 & $0.314 \mathrm{NS}$ \\
\cline { 2 - 8 } & Secondary & 1 & $2 \%$ & 0 & $0 \%$ & 1.01 & $0.314 \mathrm{NS}$ \\
\hline Velo-pharyngeal insuff. & Yes & 1 & $2 \%$ & 0 & $0 \%$ & 1.01 & $0.314 \mathrm{NS}$ \\
\hline Recurrence & Yes & 4 & $8 \%$ & 1 & $2 \%$ & 1.89 & $0.168 \mathrm{NS}$ \\
\hline
\end{tabular}

$\mathrm{X}^{2}$ : Chi-square test.

NS: p-value $>0.05$ is considered non-significant.

The average healing time was 14 days for group I (range: 13 to 15 days) and 18 days for group II (range: 17 to 20 days), which was statistically significant $(\mathrm{p}<0.001)$. This table showed high statistical significant difference ( $\mathbf{p}<\mathbf{0 . 0 0 1})$ between studied groups regarding healing time.

Table (6): Comparison between studied groups as regard healing time

\begin{tabular}{|c|c|c|c|c|c|}
\hline \multicolumn{2}{|c|}{} & $\begin{array}{c}\text { Group I } \\
(\mathbf{N = 5 0 )}\end{array}$ & $\begin{array}{c}\text { Group II } \\
(\mathbf{N = 5 0 )}\end{array}$ & T & P-value \\
\hline \multirow{2}{*}{$\begin{array}{c}\text { Healing time } \\
\text { (days) }\end{array}$} & Mean \pm SD & $14.4 \pm 2.2$ & $18.7 \pm 1.6$ & \multirow{2}{*}{11.2} & $<\mathbf{0 . 0 0 1}$ HS \\
\cline { 2 - 4 } & Range & $13-15$ & $17-20$ &
\end{tabular}

$\mathrm{T}$ : Independent sample T test.

HS: p-value $<0.001$ is considered highly significant.

\section{DISCUSSION}

We have analyzed the technique of ablation of the adenoid pad by suction electrocautery and compared it to the standard curette technique. The advantage of suction diathermy adenoidectomy over curette adenoidectomy is precise removal of adenoid tissue guided by the oral or nasal endoscopy. Adenoid tissue obstructing the choana and surrounding the eustachian tube orifice can be removed with clear visualization without bleeding ${ }^{(10)}$.

In our study, there were 62 males and 38 females. The average age of children enrolled in the study was $7.2 \pm 1.2$ years for the suction electrocautery group and $6.8 \pm 1.2$ years for the curette group. There were no statistically significant differences between these groups comparing age, which compares with the study by Na'ara et al. ${ }^{(11)}$ where the mean age of patients was 5.9 years.

There were male predominance in this study, which represent $62 \%$ males and $38 \%$ females where in the Flanary study, there were $51.6 \%$ females and 48.4 $\%$ were males ${ }^{(\mathbf{1 2})}$.

The most common presenting symptoms in this study were snoring, mouth breathing followed by OSA. These findings are not consistent with Kotecha et al. ${ }^{(13)}$ study in which the mouth breathing, snoring, rhinorrhea and cough were the main presenting symptoms.

In this study, 31 patients were diagnosed as adenoid hypertrophy, 32 patients as chronic adenotonsillitis, 19 patients as adenoid hypertrophy plus OME and 18 patients as chronic adenotonsillitis plus OME. In Skilbeck et al. ${ }^{(14)}$ study on 120 patients, 54 patients had OME and 13 patients had rhinosinusitis.

Jonas et al. ${ }^{(15)}$ mentioned that the average operative time for adenoidectomy by curette was 8.6 minutes (range: 5.4:19 minutes) and 7.5 minutes for suction diathermy adenoidectomy (range: 5.1:17.05 minutes) while in our study, the average operative time for adenoidectomy by curette was 9.9 minutes (range:
7:12 minutes) and 7.2 minutes for suction diathermy adenoidectomy (range: 4:10 minutes). Jonas $\boldsymbol{e t}$ al. ${ }^{(\mathbf{1 5})}$ mentioned that suction diathermy adenoidectomy has been shown to take up to $17 \mathrm{~min}$. The relatively long suction diathermy time in that study can possibly be explained by the relative inexperience of the surgeon with this procedure.

In our study, the average blood loss in the traditional curette group was $27.3 \mathrm{ml}$ (range: $21: 32 \mathrm{ml}$ ) and in the suction diathermy group was $5.7 \mathrm{ml}$ (range: $3: 7 \mathrm{ml})$, which is highly statistically significant $(\mathbf{p}<$ 0.001). This correlates with what Sethi et al. (16) mentioned that intra-operative blood loss with suction diathermy adenoidectomy was significantly lower than blood loss in curettage adenoidectomy $(4.1 \mathrm{ml}$ vs 24.0 $\mathrm{ml})$.

Post-operative complications in our study included post-operative hemorrhage, velopharyngeal insufficiency and recurrence. There was one case (1\%) with reactionary hemorrhage in group I with no cases in group II. In addition, there was one case (1\%) with secondary hemorrhage in group I with no cases in group II, which was managed by conservative management. While in Lowe et al. (17) study, the early and late haemorrhage risk rate for suction diathermy adenoidectomy was found to be $0.07 \%$. While, in Skilbeck et al. ${ }^{(14)}$ post-operative haemorrhage as a complication not encountered in children having adenoidectomy using suction diathermy.

There was one case (2\%) with velopharyngeal insufficiency in group I while in group 2 there was no cases with that condition. However, Witzel et al. ${ }^{(18)}$ reported that incidence of hypernasal speech after adenoidectomy alone to be as low as 1 per 10,000 and after adenotonsillectomy to be 1 per 3000. The advantage of suction diathermy adenoidectomy over curette adenoidectomy is precise removal of adenoid tissue guided by the oropharyngeal 
endoscopy preventing the occurrence of velopharyngeal insufficiency as much as possible. In addition, adenoid tissue obstructing the choana and surrounding the eustachian tube orifice was removed with clear visualization without bleeding.

In our study, recurrence of adenoid hypertrophy at the end of 6 months was found in 4 patients $(8 \%)$ of traditional group but only in one patient (2\%) of suction diathermy adenoidectomy group. According to Skilbeck et al. ${ }^{(14)}$, their results demonstrated that adenoid regrowth may sometimes occur despite visualisation of the nasopharynx and the use of the suction coagulator. On the other hand, Jonas et al. (15) mentioned that there was a significant difference in postoperative adenoidal sizes between curette and suction diathermy group. Suction diathermy showed superior reduction of the adenoidal size 6 months after surgery.

Our study demonstrated that the average healing time after adenoidectomy was 14 days for group I (range: 13 to15 days) and 18 days for group II (range: 17 to 20 days), which was statistically significant. By day 17 , the adenoid ped was covered by a layer of epithelium. The initial epithelial bridge was thickened and resembled normal mucosa with complete absence of signs of inflammation.

\section{CONCLUSION}

Traditional adenoidectomy may achieve the desired results in many patients; however, it frequently fails to obtain a complete tissue removal. Thus, it is less effective than endoscopic techniques. This new technique seems to be safe and effective. Use of suction diathermy has a few disadvantages. It requires the use of expensive equipment including the cost of the device and endoscopes. In addition, this technique requires a good training to gain experience. Therefore, we suggest suction diathermy as the most appropriate method for adenoidectomy in children. Intra-operative haemorrhage and operative time is minimized and the risk of post-operative complications was very low compared to the conventional method.

\section{RECOMMENDATIONS}

We recommend Using suction diathermy in adenoidectomy, which is better than traditional method as it is effective as traditional method but with less complications. Follow up the patients for longer periods to assess the long-term complications.

\section{REFERENCES}

1. Walker $\mathbf{P}$ (2001): Pediatric adenoidectomy under vision using suction-diathermy ablation. Laryngoscope, 111: 2173-2177.

2. Wright E, Pearl A, Manoukian J (1998): Laterally hypertrophic adenoids as a contributing factor in otitis media. Int J Pediatr Otorhinolaryngol., 45: 207-214.

3. Tarantino V (2004): Safety of electronic molecular resonance adenoidectomy. Int J Pediatr Otorhinolaryngol., 68: 1519-1523.

4. Sorin A, Bent J, April M et al. (2004): Complications of Microdebrider-Assisted Powered Intracapsular Tonsillectomy and Adenoidectomy. Laryngoscope, 114: 297-300.

5. Sugawa C (1975): Electrocoagulation of Bleeding in the Upper Part of the Gastrointestinal Tract. Arch Surg., 110: 975-81.

6. Kwok P, Hawke M. (1987): The use of suction cautery in adenoidectomy. J Otolaryngol., 16: 49-50.

7. Hartley B, Papsin B, Albert D (1998): Suction diathermy adenoidectomy. Clin Otolaryngol Allied Sci., 23: 308-309.

8. Pearl A, Manoukian J (1994): Adenoidectomy: indirect visualization of choanal adenoids. J Otolaryngol., 23: 221-4.

9. Skilbeck C, Tweedie D, Lloyd-Thomas A et al. (2007): Suction diathermy for adenoidectomy: Complications and risk of recurrence. Int J Pediatr Otorhinolaryngol., 71: 917-920.

10. Clemens J, McMurray J, Willging J (1998): Electrocautery versus curette adenoidectomy: comparison of postoperative results. Int J Pediatr Otorhinolaryngol., 43: 115-122.

11. Na'ara S, Sayegh W, Nassar W et al. (2019): Cold versus hot adenoidectomy: A prospective, randomized controlled trial. Int J Pediatr Otorhinolaryngol., 135: 110087.

12. Flanary V (2010): Long-term effect of adenotonsillectomy on quality of life in pediatric patients. Laryngoscope, 113: 1639-1644.

13. Kotecha B, Hannan S, Khalil H et al. (2007): Sleep nasendoscopy: a 10-year retrospective audit study. Eur Arch Oto-Rhino-Laryngology, 264: 1361-1367.

14. Skilbeck C, Tweedie D, Lloyd-Thomas A et al. (2007): Suction diathermy for adenoidectomy: Complications and risk of recurrence. Int J Pediatr Otorhinolaryngol., 71: 917-920.

15. Jonas N, Sayed R, Prescott C (2007): Prospective, randomized, single-blind, controlled study to compare two methods of performing adenoidectomy. Int $\mathrm{J}$ Pediatr Otorhinolaryngol., 71: 1555-1562.

16. Sethi N, Egan P, Ward V (2014): Suction diathermy adenoidectomy performed in the district general hospital. J Laryngol Otol., 128: 78-81.

17. Lowe D, Brown P, Yung M (2011): Adenoidectomy technique in the United Kingdom and postoperative hemorrhage. Otolaryngol Head Neck Surg., 145: 314318.

18. Witzel M, Rich R, Margar-Bacal F et al. (1986): Velopharyngeal insufficiency after adenoidectomy: an 8year review. Int J Pediatr Otorhinolaryngol., 11: 15-20. 